\title{
Investigation of Leakage Inductance Influence on Torque Characteristic of Different Types of Induction Machines
}

\author{
Ihor Reva, Mykhaylo Zagirnyak, Senior Member, IEEE \\ Institute of Electromechanics, energy saving, \\ and automatic control systems \\ Kremenchuk Mykhailo Ostrohradskyi National University \\ Kremenchuk, Ukraine \\ cgdizainer@gmail.com, mzagirn@kdu.edu.ua
}

\author{
Mario Vukotic, Damijan Miljavec and Selma Corovic \\ Faculty of Electrical Engineering \\ University of Ljubljana \\ Ljubljana, Slovenia \\ mario.vukotic@fe.uni-lj.si,damijan.miljavec@fe.uni-lj.si, \\ selma.corovic@fe.uni-lj.si
}

\begin{abstract}
The main objective of this study was to investigate the influence of leakage inductance of different types of induction machines on the resulting torque characteristic. The study was focused on three phase induction machines that are most often used in the industry with special emphases on the induction machine configuration with squirrel cage rotor. Based on the known analytical solutions the leakage inductance components were calculated for different types of stator and rotor geometry slots and winding profiles. Special emphasis was put on analysis and comparison of analytical solutions proposed by Pyrhönen and Boldea-Nasar. Based on the analyzed analytical solutions we developed a programing Matlab script code, which can serve as an important tool in designing and analysis the induction machine characteristics.
\end{abstract}

Keywords-induction motor, squirrel cage rotor, leakage inductance, stator and rotor slots

\section{INTRODUCTION}

Induction motors are among the most widely used machines in different industrial applications, which typically include different types of drive systems, compressors, pumps, automotive applications and many other applications including pharmaceutical and medical area [1-3]. Induction motors are most frequently designed as general purpose motors according to well defined national standards, but if however, a specific application requires additional requirements a special motor must be designed by the scientist, engineers and manufactures. Generally, the induction motors can be designed with winding rotor or with squirrel cage rotor. The latter is widely used as general-purpose motor due to its robustness and cost effectiveness. As an important tool for designing and performance analysis a specialized commercial software based on numerical modeling can be used in combination with experimental testing in laboratory and industrial settings. However, the equivalent-circuit analysis based on analytical mathematical methods also represents a powerful toll for rapid design and performance analysis of induction machines taking into account all important components such as leakage inductances, resistances, mutual inductance and their impacts on the resulting torque characteristic profile [1].

It is well established that the leakage inductance largely depends on geometrical and material properties of the induction machine. Richter $[4,5]$ was first to describe the influence of the rotor slot cross section area on the leakage inductances, which in turn influences the torque characteristic. Subsequently, the derivation of rotor and stator leakage-inductance components contribution to the torque characteristic profiles was approached by scientists in different ways. The mathematical solutions of leakage inductance components in context of complete design of induction machines have been extensively described by [6], [7]. However, it has been a challenging task to validate the analytical solutions with measurement data on different types of induction machines used in industrial applications.

The primary objective of this study was to investigate the influence of leakage inductance of different types of induction machines on the resulting torque characteristic based on the known analytical solutions proposed by [6], [7] while taking into account all contributing components of the machine leakage inductances. The leakage inductance components were calculated for different types of rotor geometry slots and stator end-winding profiles while keeping the stator slot geometry constant. The analytical analysis of stator was focused on trapezoidal shaped slot with the single layer winding and six different geometrical profiles of endwinding described in [7] and the sensitivity of the stator-slot geometry on the resulting torque. The rotor analysis was focused on five types of rotor slots such as drip shaped, trapezoidal, reversed trapezoidal, rectangular and circled rotor slots. The influence of material properties of the rotor bars on the torque profile was also analyzed. The authors investigated the influence of each leakage inductance component on the resulting torque characteristic for each type of the stator and rotor configuration. Based on this, the influence of slot geometry and winding characteristics on the machine torque normal characteristic was analyzed. The resulting torque characteristic profiles obtained using analytical solutions reported by both authors are compared between each other. The analyzed analytical solutions were implemented into a Matlab script code, which can serve as an important tool in designing and analysis the induction machine characteristics. The Matlab based machine design tool is modular and can be upgraded with other machine physical properties and easily modified for further analysis of other types of induction machines. The results obtained based on analytical solutions from literature were compared with 
experimental results performed on real induction motors used in industry.

\section{METHODS}

The analytical solutions from the literature overview were used for development of an induction machine design tool by using Matlab software environment. We specifically focused on the solutions reported by [6] and [7]. Different nomenclature was used in above mentioned papers. In our paper, IEC 60027-4 nomenclature will be used, taking into account relevant quantities from both references. The obtained results using analytical solutions are compared to the experimental data acquired from measurement on a 3phase $45 \mathrm{~kW}$ general-purpose induction motor provided by Bartec Varnost d.o.o. $\left(U_{n}=380 \mathrm{~V}, n_{n}=14781 / \mathrm{min}, f_{n}=\right.$ $50 \mathrm{~Hz}, P F=0.87$, DDY $225 \mathrm{M}-4$ ) in order to validate the developed script code.

According to $[4,5]$ approach, the total stator leakage $L_{s l}$ and rotor leakage $L_{r l}$ inductances are defined with equations (1) and (2), respectively:

$$
\begin{gathered}
L_{s l}=L_{d l s}+L_{z l s}+L_{s l s}+L_{e l s} \\
L_{r l}=L_{d l r}+L_{z l r}+L_{s l r}+L_{e l r}+L_{s k e w r}
\end{gathered}
$$

The nomenclature of the corresponding leakage inductance components appearing in the equations (1-5) is described in the Table I. The detailed equations of all leakage inductance components are available in [6] and [7].

TABLE I. Stator and rotor leakage-inductance nomenclature from the references [6] and [7]

\begin{tabular}{|c|c|}
\hline Boldea [6] & Pyrhönen [7] \\
\hline Sifferential $\left(L_{d l s}\right)$ & air-gap $\left(L_{\delta s}\right)$ \\
\hline zig-zag $\left(L_{z l s}\right)$ & tooth-tip $\left(L_{d s}\right)$ \\
\hline slot $\left(L_{s l s}\right)$ & slot $\left(L_{u s}\right)$ \\
\hline end connection $\left(L_{\text {els }}\right)$ & end winding $\left(L_{w s}\right)$ \\
\hline \multicolumn{2}{|c|}{ Rotor } \\
\hline differential $\left(L_{d l r}\right)$ & air-gap $\left(L_{\delta r}\right)$ \\
\hline zig zag $\left(L_{z l r}\right)$ & tooth-tip $\left(L_{d r}\right)$ \\
\hline slot $\left(L_{s l r}\right)$ & slot $\left(L_{u r}\right)$ \\
\hline end ring $\left(L_{e l r}\right)$ & short-circuit ring $\left(L_{r w g r}\right)$ \\
\hline skewing $\left(L_{\text {skewr }}\right)$ & skewing $\left(L_{s q r}\right)$ \\
\hline
\end{tabular}

According to [7] the general equation of total leakage inductance for stator and rotor $L_{\sigma}$ is represented by equation:

$$
L_{\sigma}=L_{s q}+L_{\delta}+L_{u}+L_{d}+L_{w}
$$

The author then divided the general equation into stator-side leakage inductance $L_{s \sigma}$ defined by equation:

$$
L_{s \sigma}=L_{\delta s}+L_{d s}+L_{u s}+L_{w s}
$$

and rotor-side leakage inductance $L_{r \sigma}$ defined by equation:

$$
L_{r \sigma}=L_{\delta r}+L_{d r}+L_{u r}+L_{r w g}+L_{s q r} .
$$

The magnetizing inductance $L_{m}$ is defined as:

$$
L_{m}=\frac{2 m \tau_{p}}{\pi^{2} p \delta_{e f}} \cdot \mu_{0} l^{\prime}\left(k_{w s 1} N_{s}\right)^{2}
$$

where $m$ stands for number of phases, $\tau_{p}$ is stator pole pitch, $p$ is number of slots per pole per phase, $\delta_{e f}$ is effective air gap, 1 is effective machine length, $k_{w s 1}$ is stator winding factor and $N_{s}$ is number of turns per phase, [6] and [7].

According to [6] the torque characteristic (i.e. torque-slip relationship $-M(s))$ is defined as:

$$
M(s)=\frac{3 \cdot U_{s}^{2} \cdot p_{1}}{\omega_{1}} \cdot \frac{\frac{R_{r}^{\prime}}{s}}{\left(R_{s}+\frac{C \cdot R_{r}^{\prime}}{s}\right)^{2}+\left(X_{s l}+C \cdot X_{r l}^{\prime}\right)^{2}}
$$

where $U_{s}$ is stator input voltage, $p_{1}$ is the number of pole pairs, $R_{r}{ }_{r}$ is rotor resistance referred to stator side, $s$ is slip, $R_{s}$ is stator resistance, $X_{s l}$ is stator leakage reactance, $X_{r l}{ }_{r l}$ is rotor leakage reactance and $C=\frac{L_{m}-L_{s l}}{L_{m}}$.

According to [7] the torque characteristics $M(s)$ is defined as:

According to [7] the torque characteristics is defined as:

$$
M(s)=\frac{3 \cdot\left[U_{s} \cdot\left(1-\frac{L_{s \sigma}}{L_{m}}\right)\right]^{2} \cdot \frac{R_{r}^{\prime}}{s}}{\frac{\omega_{s}}{p} \cdot\left[\left(R_{s}+\frac{R_{r}^{\prime}}{s}\right)^{2}+\left(\omega_{s} L_{s \sigma}+\omega_{s} L_{r \sigma}^{\prime}\right)^{2}\right]} .
$$

The described equations are implemented for the stator and rotor configurations from [8], as represented in Fig.1.

a)

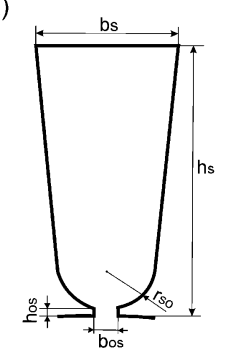

c)

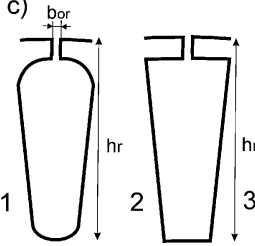

Fig. 1. The analyzed induction motor geometry: a) stator slot $\left(h_{s}=27.7 \mathrm{~mm}\right.$, $b_{s}=9.68 \mathrm{~mm}, b_{o s}=2.9 \mathrm{~mm}, h_{o s}=0.6 \mathrm{~mm}$ ); b) end-winding profiles $1,2,3$, 4,5 and 6 according to [7] and c) the rotor slot designs 1-drip-shaped, 2 -trapezoid, 3 -reversed trapezoid, 4-rectangular and 5-circled $\left(h_{r}=37.9 \mathrm{~mm}, b_{o r}=1.1 \mathrm{~mm}\right.$ and $\left.r_{b}=4 \mathrm{~mm}\right)$

The electrical conductivities of the analyzed squirrel cage materials are given in Table II $[9,10]$. 
TABLE II. The analyzed materials of the rotor squirrel-cage

\begin{tabular}{|cl|c|}
\hline \multicolumn{2}{|c|}{ Material } & Conductivity (S/m) \\
\hline 1. & Silver & $63 \cdot 10^{6}$ \\
\hline 2. & Copper (100 \% IACS) & $58 \cdot 10^{6}$ \\
\hline 3. & Gold & $45 \cdot 10^{6}$ \\
\hline 4. & AlSi7Mg & $27 \cdot 10^{6}$ \\
\hline 5. & AlSi10Mg & $25 \cdot 10^{6}$ \\
\hline
\end{tabular}

(the International Annealed Copper Standard)

The stator slot shown in (Fig. 1a) was kept constant for all calculations. For the sensitivity analysis the stator slot area was changed by $\pm 20 \%$. The profile 1 (shown in Fig. 1b) was the reference end-winding geometry for all calculations. The first design of the rotor (Fig. 1c) which represents the deep-cage slot shape was used as an approximation of the real induction machine with double-slot rotor design (keeping the slot area and slot depth $h_{r}$ the same) on which the experiments has been performed.

\section{RESULTS}

The resulting torque characteristics obtained using [11], [6] and [7] equations are compared to the measured data in Fig. 2. The results show good agreement between the theoretical torque characteristic and experimental results within the region of interest (i.e. the torque around nominal slips up to the breakdown slip). We concluded that the analytical modeling approach can be effectively used for analysis of the induction motor performance within the range of slips up to the breakdown slip. This also means that the approximation of the double-slot rotor design approximated with a deep-slot rotor shape can be used for the description of the motor performance around nominal slips. However, for the description of the starting torque, the approximation is not valid and the detailed rotor geometry has to be taken into account.
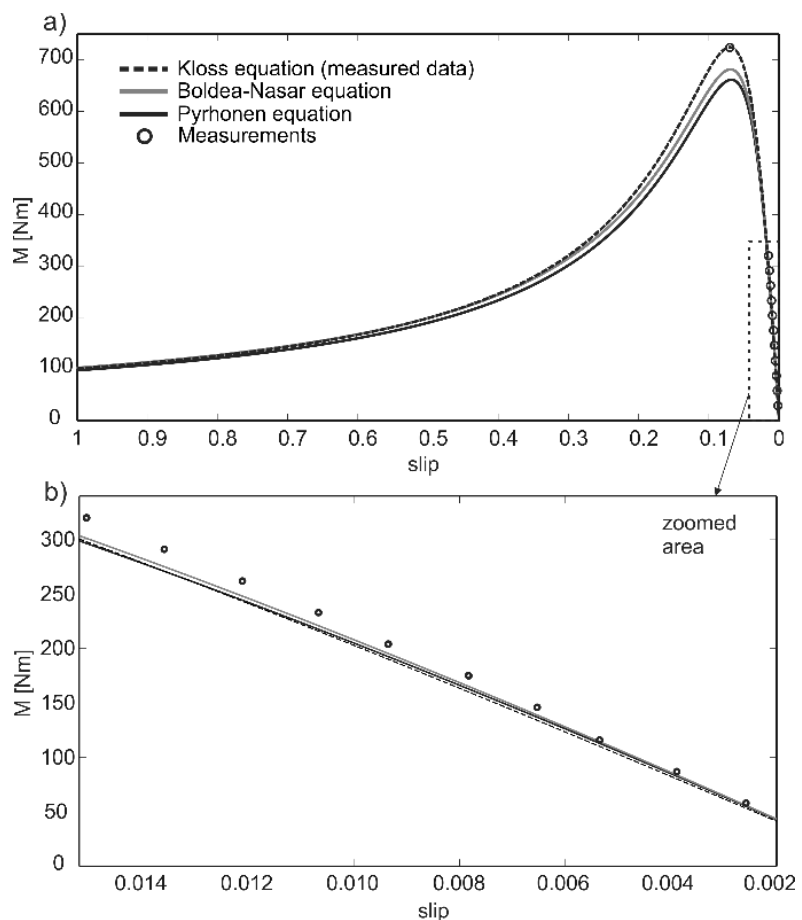

Fig. 2. a) Comparison of $M(s)$ calculated according to [7] and [6] with measurements data and b) zoomed $M(s)$ for $0.002<$ slip $<0.015$
The comparison in (Fig. 2b) also shows that the analytical solutions reported by both authors give almost equal results and their values are close to the measured data around the nominal slip $\left(M_{n}=291 \mathrm{Nm}\right.$ at $\left.s_{n}=0.0147\right)$. In the continuation of this study, we focused on the equations from [7], since they are comprising more geometrical parameters.

The comparison of the torque characteristics obtained with six different end-winding profiles (Fig. 1b) for the constant stator slot (Fig. 1a) and the reference rotor slot (Fig. 1c-design 1) is shown in Fig. 3. The results show that the $M(s)$ slightly depends on the end-winding profile. The reference end-winding profile results in the highest torque compared to the remaining five end-winding profiles. The comparison is more precisely represented in the Table III. The Table III also summarizes the empirically determined permeance factors of the end-windings reported in [7].
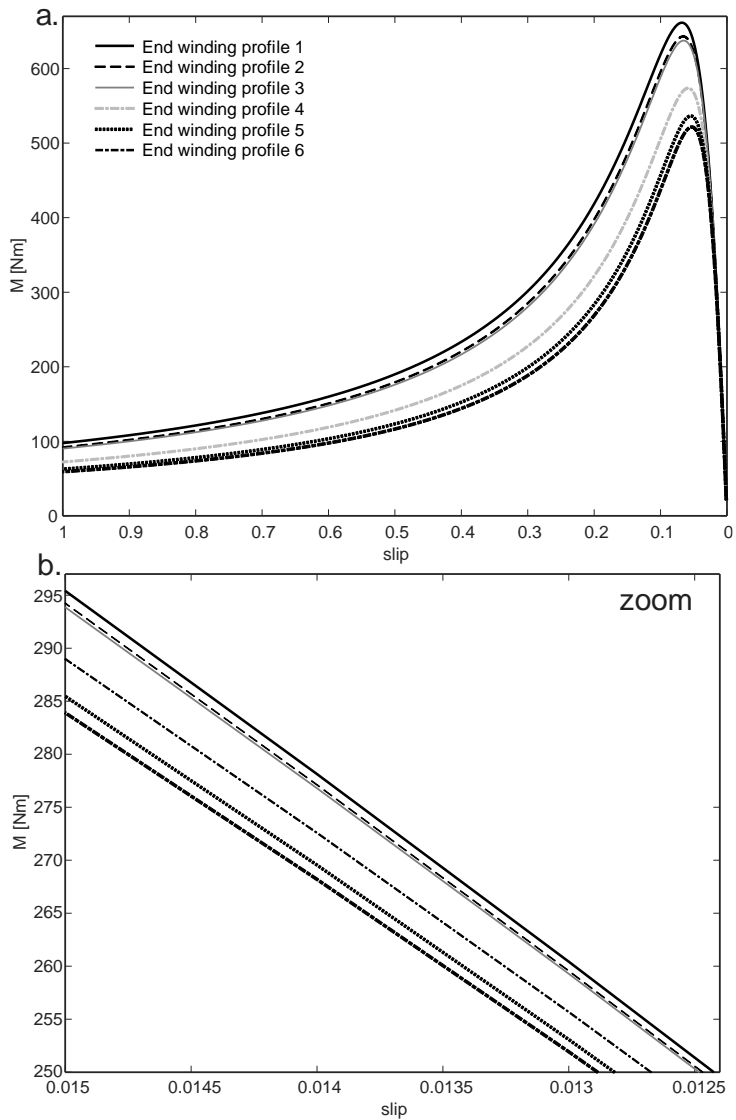

Fig. 3. $M(s)$ calculated with different end-windings profiles [7]: a) $M(s)$ for $0<\operatorname{slip}<1$ and b) zoomed segment for $0.0125<s<0.015$

TABLE III. The values of the permeance factor according to [7] and the calculated $M(s)$ for all analyzed end-winding geometries

\begin{tabular}{|c|c|c|c|}
\hline$\lambda_{e w}$ & $\lambda_{w}$ & $M(\mathrm{Nm}), s=0.0147$ & $M(\mathrm{Nm}), s=0.07$ \\
\hline 0.342 & 0.413 & 290 & 661.50 \\
\hline 0.380 & 0.130 & 288.79 & 637.51 \\
\hline 0.371 & 0.166 & 289.15 & 643.10 \\
\hline 0.493 & 0.074 & 284.12 & 573.84 \\
\hline 0.571 & 0.073 & 280.75 & 536.46 \\
\hline 0.605 & 0.0028 & 279.25 & 521.63 \\
\hline
\end{tabular}

As already stated we carried out the sensitivity analysis of the torque characteristic in function to the stator slot leakage inductance $L_{u s}$ variation considering solution from [7]. The results are shown in Fig. 4. The purpose of the sensitivity 
analysis was to investigate the torque if the stator slot area changes due to numerical errors imposed for example by a coarse mesh of finite elements and/or by imperfections caused by technological processing. The torque decreases with increase of the $L_{u s}$, however, this change is negligible within the area of nominal operation.

The comparison of torque characteristic profiles obtained with five different rotor slot designs (Fig. 5) shows that the resulting torque using rotor with circled rotor slot design significantly differs from other slot types since its purpose is to produce larger starting torques. Other slot designs produce almost equal torque profiles within the nominal slip range up to the breakdown slip.

The resulting torque characteristics using different materials (given in Table II) of the reference rotor squirrel-cage is shown in Fig. 6.

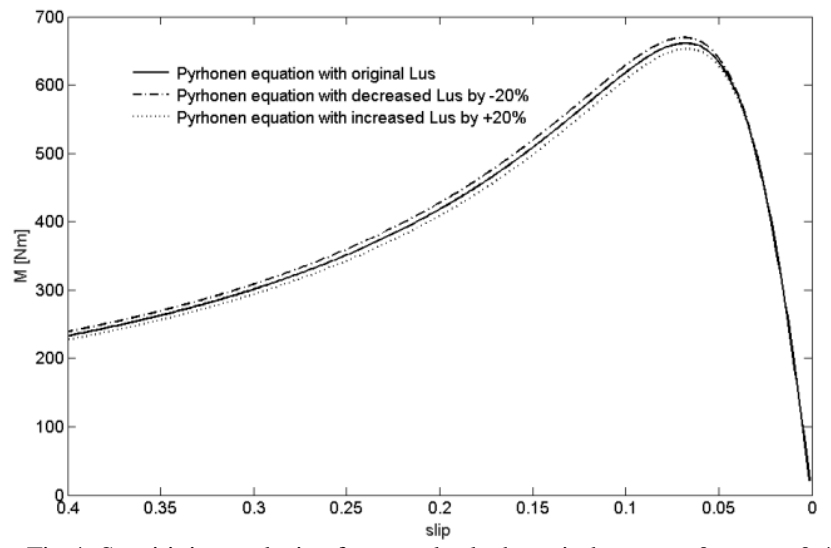

Fig 4. Sensitivity analysis of stator-slot leakage inductance: $0<s<0.4$

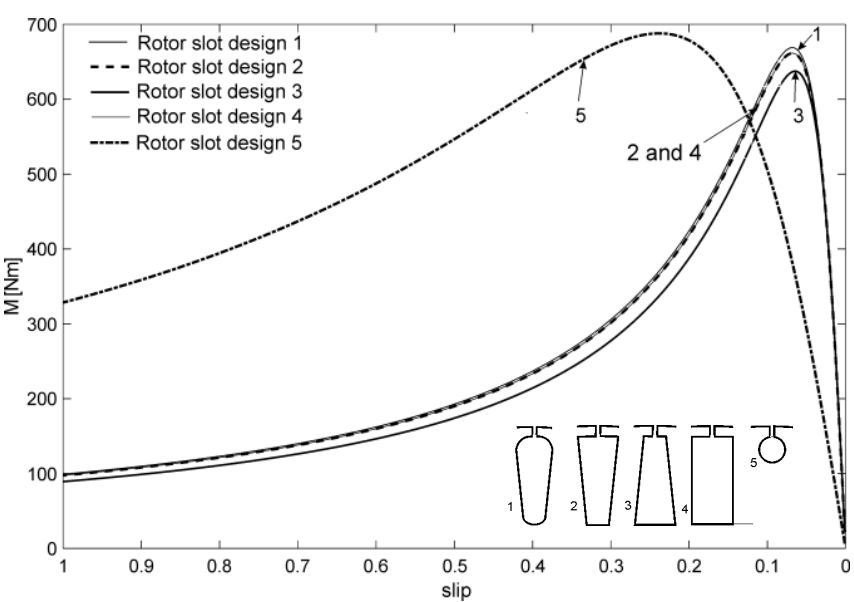

Fig. 5. The torque characteristics obtained with different rotor-slot designs

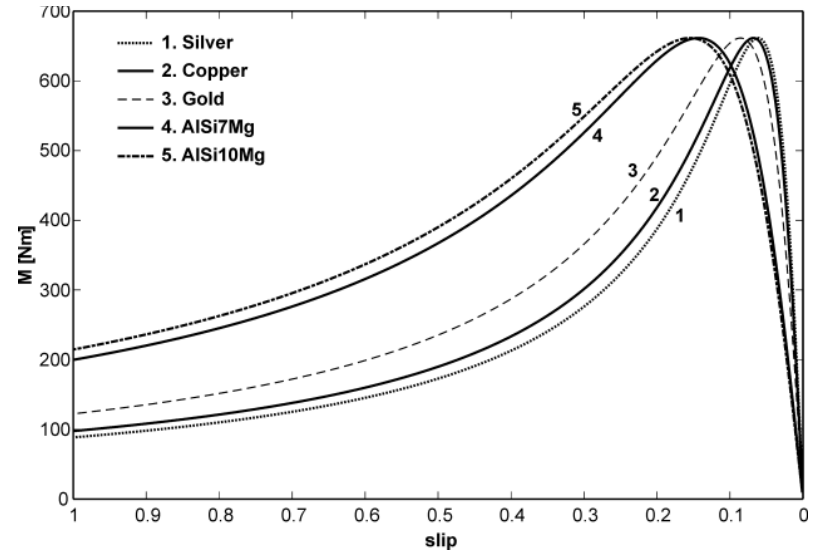

Fig. 6. Comparison of torque characteristics obtained with different material properties of the reference rotor squirrel cage given in Table II

\section{CONCLUSIONS}

The authors have developed a design tool by implementing analytical solutions for calculation of torque characteristic by taking into account geometrical and material properties of the induction machine. A detailed overview on existing analytical solutions for induction machine design with focus on analysis of leakage inductance influence on the torque characteristics has been performed. Based on the collected analytical equations the Matlab script code was developed which can serve as an important tool in designing the induction machine and analyzing its characteristics. The theoretical approach was validated and confirmed by good agreement between analytical solutions and measurements performed on real induction machine used in industry. The authors confirmed that the machine with double cage can be approximated with a single deep-slot design keeping the slot area and the slot depth the same for an approximate analysis of torque characteristic within the nominal operation range up to the breakdown torque. This means that the analytical methods can be effectively used in order to avoid more complex and often time-consuming numerical simulations. The study can be further extended by confirmation of $2 \mathrm{D}$ and/or 3D numerical modeling, with experimental data measured on other types of induction machines.

\section{ACKNOWLEDGMENT}

The authors would like to thank the Bartec Varnost d.o.o. for providing us with experimental data and Aleš Majcen M.Sc. for valuable discussion and suggestion regarding analysis of experimental results. The authors also acknowledge the EU project VISION-xEV, Virtual Component and System Integration for Efficient Electrified Vehicle Development, which has received funding from the European Union's Horizon 2020 research and innovation program under the grant agreement No 824314. The article was published as the result of the work which was conducted within the framework of the Erasmus+Exchange program.

\section{REFERENCES}

[1] M. Zagirnyak, V. Prus, D. Miljavec. "Improved method for calculation of parameters of electromagnetic and power processes in electric circuits with steel in saturation mode", Technical Electrodynamics, vol. 2015, no. 4, pp. 12-18, 2015.

[2] D. Miljavec, M. Zagirnyak and B. Zidarič, "Rotor-design and on-line starting-performance analysis of a synchronous-reluctance motor", COMPEL - The international journal for computation and mathematics in electrical and electronic engineering, vol. 28, no. 3 , pp. 570-582, 2009. 
[3] M. Zagirnyak, R. Pai and S. Nasar, "Analysis of tubular linear induction motors, using the concept of surface impedance", IEEE Transactions on Magnetics, vol. 21, no. 4, pp. 1310-1313, 1985.

[4] R. Richter. Electrical Machines: Induction Machines (Elektriche Maschinen: Die Induktionsmaschinen), 1954, vol. IV, 2nd edn, Birkhauser Verlag, Basle and Stuttgart.

[5] R. Richter. Electrical Machines: General Calculation Elements. DC Machines (Elektrische Maschinen: Allgemeine Berechnungselemente. Die Gleichstrommaschinen), 1967, vol. I, 3rd edn, Birkhauser Verlag, Basle and Stuttgart.

[6] I. Boldea, S.A. Nasar. The Induction Machines Design Handbook, Second Edition. CRC Press: Taylor \& Francis Group, 2010. 845 p.
[7] J. Pyrhönen, Tapani Jokinen and Valeria Hrabovcova. Design of Rotating Electrical Machines, First Edition. John Wiley \& Sons, Ltd, 2008, 531 p.

[8] Kienle + Spiess, Cataloge for the manufacture of electrical machines, Germany, 1989, p.1087.

[9] I.P. Uliasz, T. Knych, M. Piwowarska, J. Wiechec. "The influence of heat treatment parameters on the electrical conductivity of AlSi7Mg and AlSi10Mg aluminum cast alloys", 13th International Conference on Aluminum Alloys (ICAA13), 2012, p. 132

[10] Nipon light metal company:

https://www.nikkeikin.com/products/board/p11.html

[11] R. Fischer: Elektrische Maschinen. 14. Auflage. Hanser, 2009, p. 230, ISBN 978-3-446-41754-0. 